\title{
Evaluation of Mechanical Properties and Microstructure of AA3003, AA6082 and AA64430 Aluminum Under Friction Stir
}

\author{
M. Rajasekhar, G. Anji Babu, C. Venkata Sai Sekhar, M.Giresh Naidu
}

\begin{abstract}
Aluminum compounds are an remarkable alternative for decreasing the price, weight supplanting steels in severa applications and Friction Stir Welding procedure is a financially savvy and a green technique. Grinding blend welding is a strong nation joining method that uses a non-consumable turning welding equipment to create plastic disfigurement and frictional warm temperature at the location of the welding; along those lines, the material that is in the strong kingdom is motivated by using the use of the development of a joint. Grating blend welding is all around utilized for turning into a member of $A l$ compounds for marine automobile, aviation and numerous wonderful uses of agency significance. This exam is to get the parameters which might be ideal for the substances under contemplations, to explore the Heated Affected sector (HAZ), Thermo - Mechanical Affected zone (TMAZ) and Nugget area (NZ) aside from to consider the imperfections going on during welding system by utilising numerous parameters picked, recognise the smaller scale auxiliary changes and mechanical houses of touch blend welding of disparate aluminum joints approximately thickness is $4 \mathbf{m m}$, the aluminum divergent joints (AA3003-AA64430), (AA3003-6082) and (AA64430-AA6082) had been finished under a similar welding parameters are $2000 \mathrm{rpm}$ (rotational pace) and eleven $\mathrm{mm} / \mathrm{min}$ (transverse tempo) on vertical processing device. wherein rectangular tool is carried out. The gadgets are made on a Lathe gadget. This take a look at builds up the welding time table and technique parameters for best welds AA3003-AA6082-AA64430 aluminum utilizing tool H13 chrome steel. After the elements are welded with the aid of the use of welding, wonderful trial of pragmatic nature are accomplished at the elements which may be welded which includes the stress, Fatigue check, Hardness check, microstructure study.
\end{abstract}

\section{PRESENTATION}

Grating combination welding is a strong country method which infers that whenever of the device the cloth have to inside the sturdy kingdom .Friction aggregate welding is every different microstructure trade system, which relies upon at the erosion mixture welding which changed into created through manner of The Welding Institute (TWI) of united kingdom in 1991.Friction combo welding has as of late modified right into a profoundly precious apparatus of homogenizing and refining of the shape of the grain of the metal. it has been accounted for that FSW incredibly enhancements terrific versatility in numerous AL combos. In

Revised Version Manuscript Received on August 19, 2019.

M. Rajasekhar, Department of Mechanical Engineering, GIT, GITAM, Visakhapatnam, Andhra Pradesh, India.

G. Anji Babu, Department of Mechanical Engineering, GIT, GITAM, Visakhapatnam, Andhra Pradesh, India.

C. Venkata Sai Sekhar, Department of Mechanical Engineering, GIT, GITAM, Visakhapatnam, Andhra Pradesh, India.

M.Giresh Naidu, Department of Mechanical Engineering, GIT, GITAM, Visakhapatnam, Andhra Pradesh, India.
FSW an uncommonly established turning barrel fashioned instrument that involves a stick and shoulder that have measurements similar to the sheet thickness. The stick of the turning tool is dove into the sheet fabric and the shoulder comes into touch with the outdoor of the sheet, and later on navigates inside the satisfactory direction. The touch between the pivoting device and the sheet create warmth which lighten up the fabric beneath the dissolving purpose of the sheet and with the mechanical blending brought about via the use of the stick, the fabric inside the prepared sector reports critical plastic twisting yielding a powerfully recrystallized high-quality grain microstructure.

\section{EXPLORATORY PAINTINGS}

The materials

Picked substances for Friction blend welding tool are aluminum 3003, 64430 and 6082 having duration a hundred $x$ $50 \mathrm{x}$ four modified into taken from the organisation. The concoction game plan of the bottom material are appeared in Tables 1, 2 and three for my part. the desired length plates of $50 \mathrm{~mm}$ massive and a hundred $\mathrm{mm}$ long were taken from the sheet. The goal machining the 2 elements of the plates became to lead them to parallel For the FSW gadget bracing framework. The parallel plates empowered the consistency in welding the holes between the plates.

\begin{tabular}{|l|l|l|l|l|l|l|l|}
\hline Sl.no & $\begin{array}{l}\text { sample } \\
\text { identification }\end{array}$ & $\mathrm{Si} \%$ & $\mathrm{Fe} \%$ & $\mathrm{Cu} \%$ & $\mathrm{Mn} \%$ & $\mathrm{Zn} \%$ & $\mathrm{Al} \%$ \\
\hline 1 & $\begin{array}{l}4 \mathrm{~mm} \\
\text { Thickness Al } \\
\text { plate }\end{array}$ & 0.52 & 0.3 & 0.94 & 1.04 & 0.02 & $\mathrm{Rem}$ \\
\hline
\end{tabular}

Table 1Compositions of aluminium alloy 3003

\begin{tabular}{|l|l|l|l|l|l|l|l|l|l|}
\hline Sl.no & $\begin{array}{l}\text { Sample } \\
\text { identification }\end{array}$ & $\mathrm{Cu} \%$ & $\mathrm{Mg} \%$ & $\mathrm{Si} \%$ & $\mathrm{Fe} \%$ & $\mathrm{Zn} \%$ & $\mathrm{Cr} \%$ & $\mathrm{Ti} \%$ & $\mathrm{Al} \%$ \\
\hline 1 & $\begin{array}{l}4 \text { mm } \\
\text { thickness Al } \\
\text { plate }\end{array}$ & 0.019 & 0.88 & 1.12 & 0.33 & 0.008 & 0.017 & 0.005 & $\mathrm{Rem}$ \\
\hline
\end{tabular}

Table 2 Composition of Aluminium Alloy 64430

\begin{tabular}{|l|l|l|l|l|l|l|l|l|l|}
\hline Sl.no & $\begin{array}{l}\text { Sample } \\
\text { identification }\end{array}$ & $\mathrm{Cu} \%$ & $\mathrm{Mg} \%$ & $\mathrm{Si} \%$ & $\mathrm{Fe} \%$ & $\mathrm{Zn} \%$ & $\mathrm{Cr} \%$ & $\mathrm{Ti} \%$ & $\mathrm{Al} \%$ \\
\hline 1 & $\begin{array}{l}4 \mathrm{~mm} \\
\text { thickness Al } \\
\text { plate }\end{array}$ & 0.023 & 0.91 & 1.09 & 0.275 & 0.014 & 0.017 & 0.006 & $\mathrm{Rem}$ \\
\hline
\end{tabular}

Table 3 Composition of Aluminium Alloy 6082 example making plans 
Elastic and exhaustion test examples had been readied using a processing tool as pursue: First, examples have been observed sliced opposite to weld line with a hundred lengthy and $25.5 \mathrm{~mm}$ width, at that factor Machining the examples edges to twenty-five $\mathrm{mm}$ width. From that issue ahead, the weldment countenances had been machined to expel flashes and strain riser the instance profile modified into gotten the use of a processing gadget with a completely unique equipment to accomplish instance geometry as per the same vintage ASTM E8M-04.

\section{Welding device}

The tool should be produced the usage of a fabric which could face up to the approach and provide enough frictional warmth age. when deciding on a fabric from which to provide the FSW tool the cloth to be welded want to be considered. The tool material need to be properly extra grounded and more wear safe than the material to be welded and must likewise have a higher liquefying temperature. A customizable stick tool crafted from $\mathrm{H} 13$ tool metal became welding have become finished on the vital established order of hardware shape in Vijayawada.

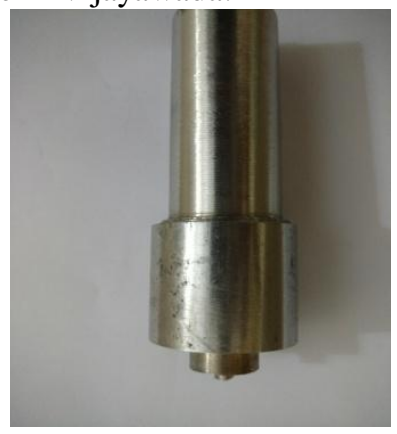

Fig 1 Friction tool

\section{Process Parameters}

in this research, erosion combo welding become completed via utilizing an I-combo 10 Multi Axis grinding aggregate welding framework. For all the specific joints created, 6082 plate were set at the propelling facet and 3003 turned into on the taking flight issue of the weld. The weld system parameters (as exhorted from FS welder) have been, Rotational speed of 2000RPM, travel speed of $11 \mathrm{~mm} / \mathrm{min}$, Forge pressure of $8 \mathrm{KN}$.

\section{INSPECTIONS AND CHECKS}

\section{A. Mechanical check}

Tractable assessments had been conveyed by way of the use of Instron all inclusive test arrangement of version $8800 R$. Elastic and yield quality become gotten from stress strain bends of the welded joints. The stress check is one of the most commonly utilized assessments for assessing materials. In its least difficult shape, the stress test is practiced thru grasping a ways edges of a check element inside the heap casing of a check gadget. A malleable energy is hooked up with the aid of the gadget, bringing about the steady prolongation and viable smash of the check element. during this procedure, strength growth information, a quantitative percentage of the manner the test component disfigures below the connected tractable strength, typically are discovered and recorded utilized for the welding exams as regarded in Fig. 1. The

Microhardness exams were executed the use of a Rockwell hardness analyzer, in which 5 traces have been taken in the cross section of weld to consider the microhardness profiles crosswise over mid-thickness of grating mix weldment. The estimations were concerned with a keeping apart of $1 \mathrm{~mm}$ from factor to point with associated heap of $1 \mathrm{Kg}$ and span time of $152 \mathrm{~d}$ modified into implemented. Rockwell hardness checking out equipment the Rockwell hardness take a look at method comprises of indenting the test material with a jewel cone or solidified metal ball indenter. The indenter is constrained into the check fabric beneath a essential minor burden F0 commonly 60kgf. at the aspect while harmony has been come to, a demonstrating machine, which pursues the development of the indenter consequently reacts to adjustments pinnacle to backside of entrance of the indenter, is prepared to a datum feature. on the factor whilst the primer burden is as but related, a noteworthy burden is connected with coming approximately increment in infiltration. at the point at the same time as concord has again been come to, the extra actual burden is evacuated however the primer minor burden remains remained. Evacuation of extra real burden permits a midway recovery, so lessening the profundity of front. The perpetual increment inner and out of front, coming about because of the software program and expulsion of the greater real burden is implemented to check the Rockwell hardness variety.

weak spot checking out modified into completed at a room temperature of roughly $20^{\circ} \mathrm{C}$, strain percentage $\mathrm{R}=$ zero.five and recurrence of $50 \mathrm{~Hz}$ in studies facility air.The weariness examples are especially indistinguishable in shapes and measurements to the elastic examples. three exams had been accomplished at each heap condition. checks had been removed from contrary region to the weld line of welded plate to run the take a look at. weak point assessments were finished on a comparable device that was applied for strain exams however with normal abundancy, sinusoidal exhaustion stacking. A weak spot life of more than $2 \times 106$ cycles changed into regarded as a run-out check. the connection between the amount of cycles and stress abundancy became separated for the unidentical FSW aluminum amalgams.

\section{B. Field Emission Scanning Electron Microscope}

A field-emanation cathode inside the electron firearm of a filtering electron magnifying lens encourages smaller sorting out pillars at insignificant just as excessive electron power, bringing approximately every progressed spatial dreams and low instance charging and harm. For applications that require the maximum incredible amplification achievable the thing is tested by means of electrons in reference to a crisscross format. Electrons are transmitted from a area outflow supply and quickened in a high electrical vicinity slope. inside the high vacuum section these socalled crucial electrons are focussed and redirected by way of the use of digital focal elements to create a constrained sweep pillar that barrages the object. therefore non-compulsory electrons are unfastened of every spot at the item. discipline discharge analyzing electron 
microscopy (FESEM) gives geological and essential data at amplifications of $10 x$ to $300,000 x$, with basically boundless profundity of area. apparently with inspecting electron microscopy (SEM), subject emanation SEM (FESEM) gives extra clean, less electro statically mutilated pix with spatial desires right down to $1 / 2$ of nanometres -3 to a couple of times better.

\section{OUTCOMES AND RESULTS}

\section{AA3003-AA6082}

The microstructure of the one of a kind territories of the welded unique material is seemed in Fig. 2 (an e). furthermore, the best and cozy cycle, has remarkably inspired the warmth encouraged quarter (HAZ), which is plain from the microstructure (Fig $2(\mathrm{a}, \mathrm{c})$ ). Be that as it may, there can be no plastic disfigurement taking place right right here. in the thermomechanically inspired location (TMAZ), which is unmistakable from the microstructure (Fig $2(\mathrm{~d}, \mathrm{e})$ ).there may be markable development in the grain limits which may be an instantaneous give up result of the plastic misshapening and the low warmth created all through the approach. Likewise, it's miles obvious from the microstructure that a particular grain restrict walls the recrystallized quarter (weld nugget) from the twisted zones of the TMAZ. The powerfully recrystallized location is the mixed location, in which the material has been uncovered to extreme plastic twisting offering ascend to extremely good likened grains. The term mixed sector is commonly rehearsed in grinding mix getting equipped, in which do the trick quantity of cloth is treated. further from the microstructure of the weld piece (Fig 2 (b)), simply the grains are pretty subtle, that could enhance the nice of the weldment. The microstructure of the artwork piece, the velocity to $2000 \mathrm{rpm}$ and welding fee to eleven $\mathrm{mm} / \mathrm{min}$ and square device.Fig.2 shows the form of aluminum aggregate 6062 of the show observed that the form grain development. The structure of this grain improvement impacts the pliancy. similarly from the microstructure of the weld piece (Fig 2 (b)), it's far unmistakable that the grains are as a substitute subtle, that would enhance the first-class of the weldment. Fig.2 (b) demonstrates the microstructure of the weld will see that some locales of the white is aluminum composite of 6080 and darkish is aluminum combination of 3003. a touch clean location is to be a bit of the aluminum composite 6082, this is excluded in chew the aluminum compound.

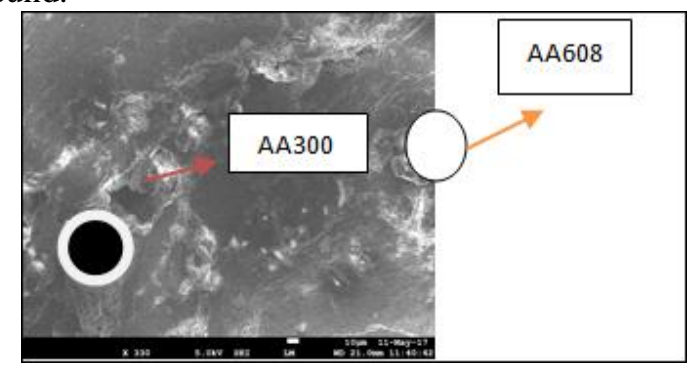

a)AA6082HAZ
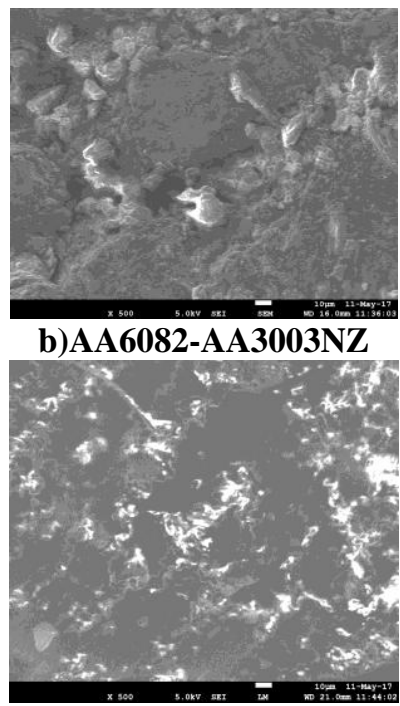

c) AA3003 HAZ

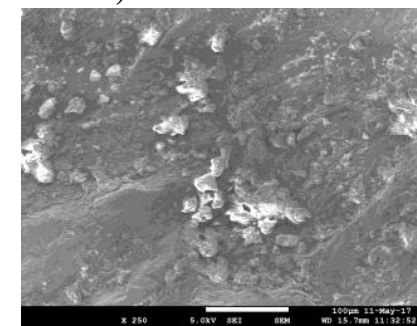

d) AA6082 TMAZ

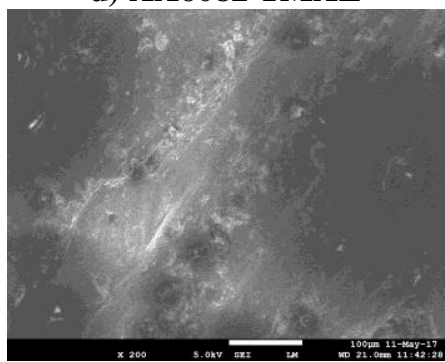

e)AA3003TMAZ

Fig 2 FESEM images of AA6082-AA3003 on different locations of the welding joint

\section{AA6082-AA64430}

The microstructure of the main of-a-sort territories of the welded assorted material is appeared in Fig.Three (an e). Rather, the warm cycle, has essentially affected the warm temperature influenced quarter (HAZ), which is plain from the microstructure (Fig three $(\mathrm{a}, \mathrm{c})$ ). Notwithstanding, there might be no plastic distortion emerging in this area. In the thermo-precisely influenced zone (TMAZ), which will be obvious from the microstructure (Fig3 $(\mathrm{d}, \mathrm{e})$ ). There's broad upgrade inside the grain snags which might be a result of the plastic distortion and the base warmth progressed sooner or later of the framework. Furthermore, it is obvious from the microstructure that a splendid grain limit isolates the recrystallized zone (weld piece) from the disfigured zones of the TMAZ. The progressively recrystallized zone is the mixed district, wherein the texture has outperformed by means of extreme plastic distortion bringing about top notch compared grains. 


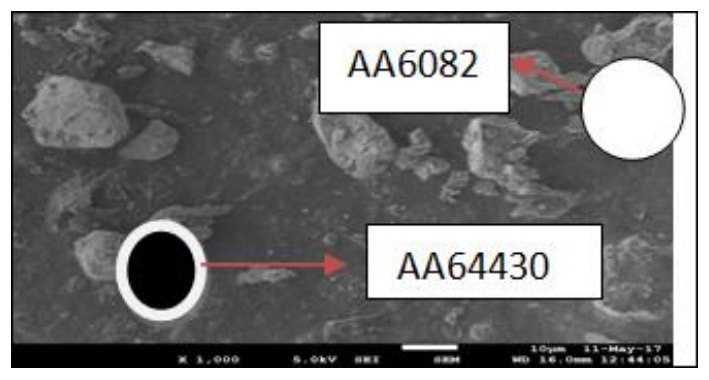

a)AA6082HAZ

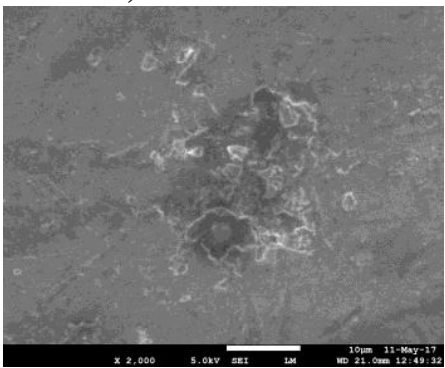

b) AA6082-AA64430 NZ

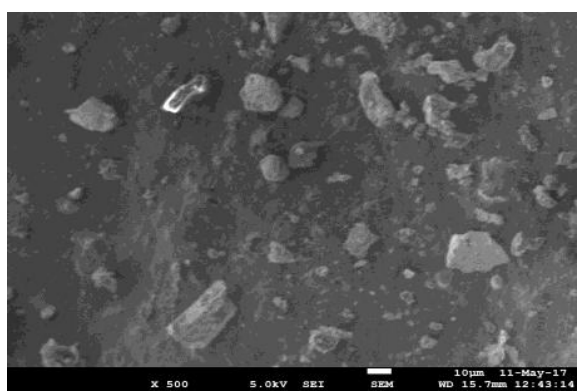

c) AA64430 HAZ

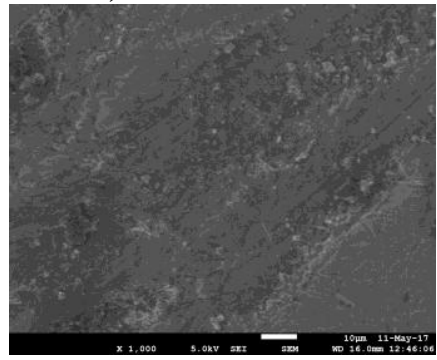

d) AA6082TMAZ

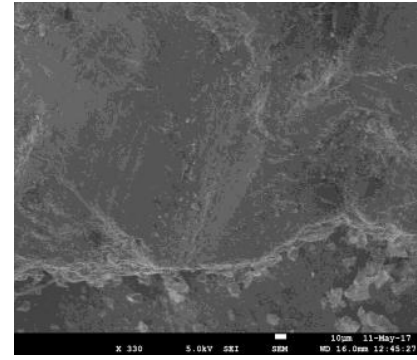

e)AA64430TMAZ

Fig 3 SEM images of AA6082-AA64430 on different locations of the welding joint

The term mixed zone is for the most part utilized in erosion mix preparing, where enough volume of material is handled. Unmistakably the grains are exceptionally refined,which could enhance the quality of the weldment, the microstructure of the work piece, the speed to $2000 \mathrm{rpm}$ and welding velocity to $11 \mathrm{~mm} / \mathrm{min}$ and square apparatus. Fig.5.8 demonstrates the structure of AA6082 AA64430 aluminum combination 6062 of the show taken that the structure grain development. The structure of this grain development impacts the rigidity. Likewise, from the microstructure of the weld piece (Fig 5.7 (b)), clearly the grains are exceptionally refined, which could improve the quality of the weldment. Fig. 5.7 (b) demonstrates the microstructure of the weld will see that a few regions of the white is aluminum composite of 6082 and dark region is aluminum combination of 64430. A little blank area is relied upon to be a piece of the aluminum amalgam 6082, which is excluded in chunk the aluminum combination.

\section{TENSILE TEST RESULTS}

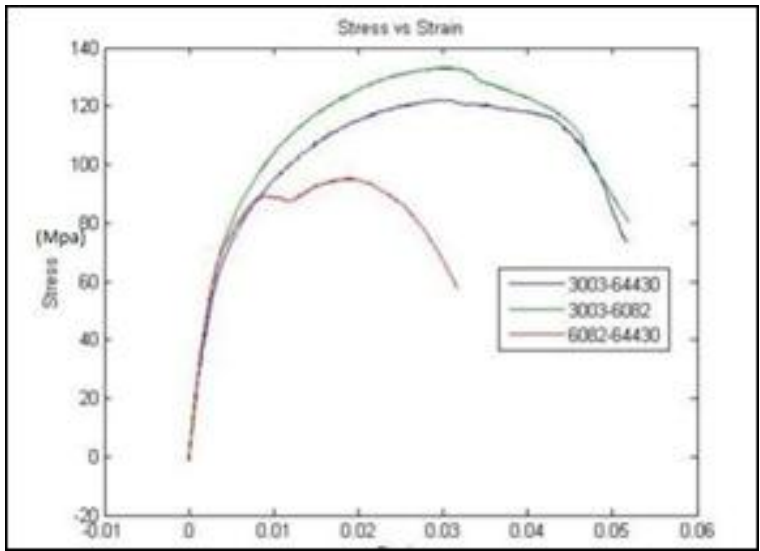

Fig 4Tensile test for strain vs. stress

The expertise of the mechanical residences of the same friction stir welds among aluminium 3003,64430,6082 is of significance to beautify their use inside the industries. The above graph that's drawn between stresses vs. stress on X-Y axis respectively.inside the above three aluminium joints if we determined truly that the joint of 6082-64430 were given less tensile power in comparison to the other aluminium joints, as well as the aluminium joint of 3003-6082 were given the most weld electricity of $132 \mathrm{Mpa}$ and it became acquired when the tool rotational pace is $2000 \mathrm{rpm}$, and the journey pace is $11 \mathrm{~mm} / \mathrm{min}$.that may sustain more load and displaying outstanding tensile homes while in comparison to other joints.

\section{FATIGUE TEST RESULTS}

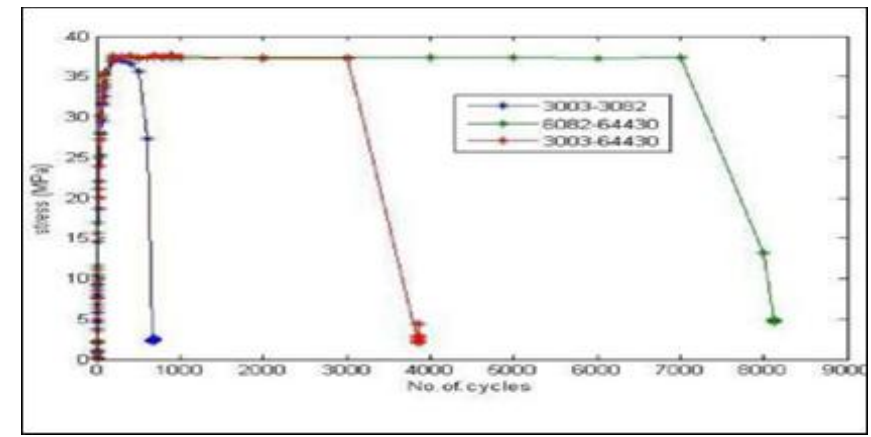

Fig 5 Fatigue comparison of welded joints

The above diagram that's seemed among quantity of cycles on X-hub and weight on Y-pivot in which joint AA6082-AA64430 received maximum severe honestly worth and which may be withstand to excellent heap of makes use of and had been given quality sort of weariness

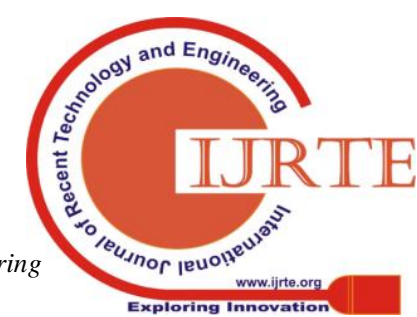


lifestyles even as contrasted with specific joints. The weariness first-class of the joint $6082-644304 \mathrm{MPa}$ at 8100 cycles. The consequences furthermore showcase that sadness at given No. Of cycles happens at lower strain sufficiency for exams in FSW condition, even as contrasted with that for pliable examples.

\section{HARDNESS PROFILE}

The below diagram it's seems among Rockwell hardness range on Y-hub and pinnacle ways from the weld centreline on X-pivot. Rockwell hardness exams had been led over the specific districts of the weld dividing of $1 \mathrm{~mm}$. on the off risk that we are watched the diagram the zero point at the middle thing, it is referred to as Nugget region. in this location hardness is much much less, because of through then most high temperature obtained because of the fast of the rotational tool and material softening greater by then whilst comparison with first rate locales. As we looked at the hardness at left 1/2 of the bottom fabric contrasted with the piece location in which left side and proper half of of of the bends demonstrates the frequently growing the hardness of the substances from the chunk area. Left half of the joint hardness is sixty .5RHN at the base metal of AA3003 and proper half of of of the joint hardness is sixty four.5RHN at the bottom metallic of AA64430.Above diagram inferred that joint AA3003-AA64430 hardness number is $64.5 \mathrm{RHN}$.

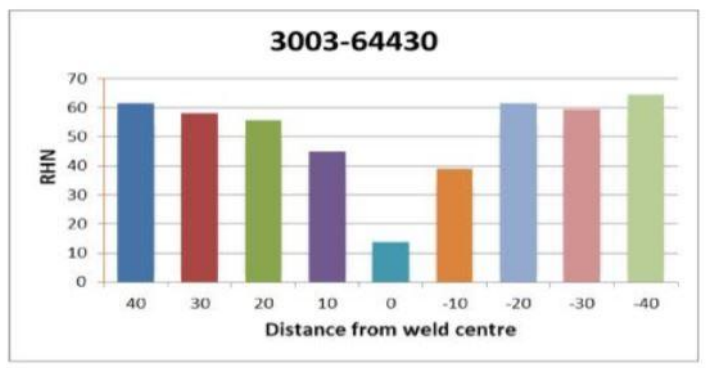

Fig 6 Hardness test on Aluminium weld joint of 3003-64430

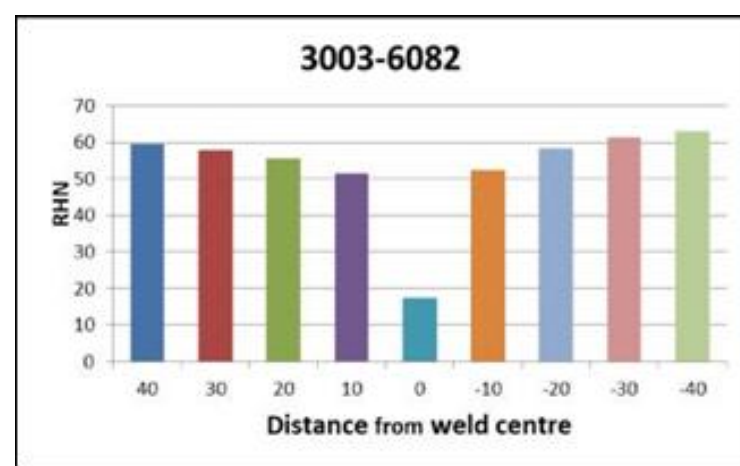

Fig 7 Hardness test on Aluminium weld joint of 3003-6082

The above diagram which is appears among Rockwell hardness range on Y-hub and suitable methods from the weld centreline on $\mathrm{X}$-pivot. Rockwell hardness exams were led over the unique districts of the weld dispersing of $1 \mathrm{~mm}$. within the occasion that we're watched the chart the 0 factor at the middlepoint, it is called Nugget area. in this place hardness is less, because of via the usage of then greatest temperature obtained because of the fast of the rotational device and fabric softening more via then whilst contrast with one-of-a-kind locales. As we idea about the hardness at left half of of of the lowest cloth contrasted with the chew sector in which left side and proper half of of the bends demonstrates the little by little increasing the hardness of the substances from the piece quarter. Left $1 / 2$ of of the joint hardness is fifty nine.5RHN at the bottom metallic of AA3003 and right half of of the joint hardness is sixty three.5RHN at the lowest metallic of AA6082. The above chart presumed that joint AA3003-AA6082hardness range Is 63.5RHN.
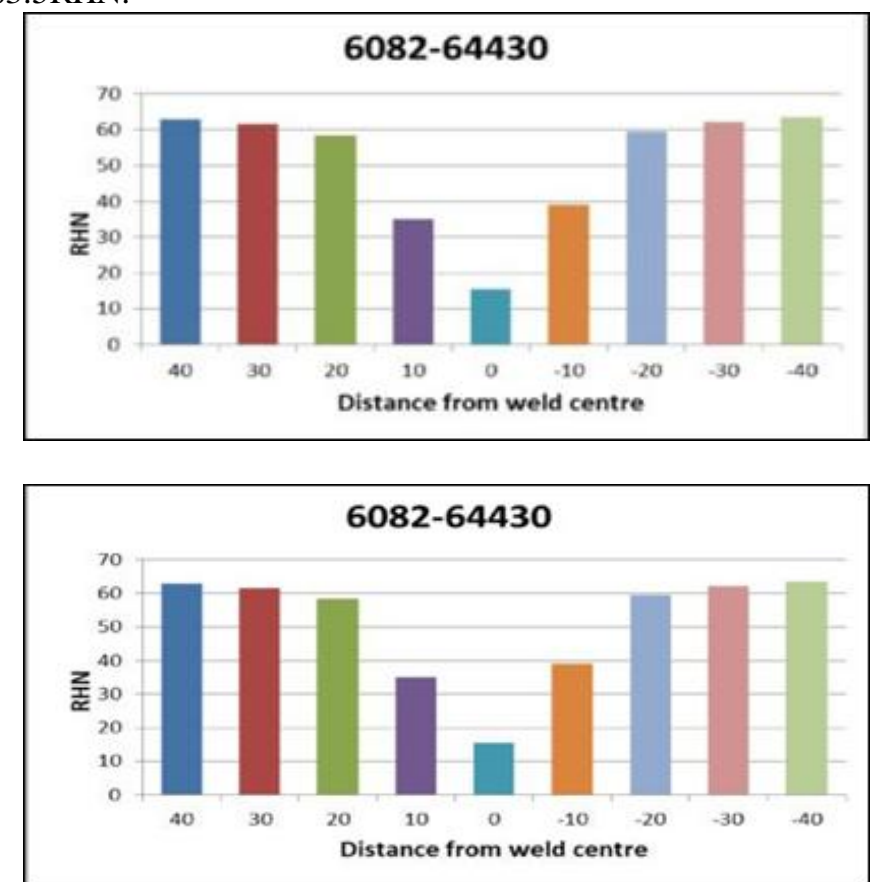

Fig 8 Hardness test Aluminium on weld joint of 6082-64430

The above diagram that's appears among Rockwell hardness quantity on Y-pivot and pinnacle methods from the weld centreline on X-hub. Rockwell hardness exams were led over the one-of-a-kind locales of the weld setting apart of $1 \mathrm{~mm}$. at the off risk that we are watched the chart the zero issue at the middle component, it's miles called Nugget area. in this vicinity hardness is less, due to via then most hot temperature acquired because of the rapid of the rotational tool and material dissolving extra thru then whilst contrast with certainly one of a type locales. As we notion about the hardness at left half of of the bottom cloth contrasted with the chew vicinity in which left facet and right half of the bends demonstrates the slowly increasing the hardness of the substances from the piece sector. Left $1 / 2$ of the joint hardness is sixty one.5RHN at the bottom metal of AA6082 and proper $1 / 2$ of the joint hardness is sixty two.5RHN at the lowest metallic of AA64430. The above diagram inferred that joint AA3003-AA64430 hardness variety is 62.5RHN.

\section{CONCLUSIONS}

1. Base metal AA3003, AA6082, AA64430 was observed to illustrate the top notch characteristics for Friction Stir Welding. For the given association of impediments, the excellent parameters were decided to be device revolution velocity as $2000 \mathrm{rpm}$, welding tempo as $11 \mathrm{~mm} / \mathrm{min}$.

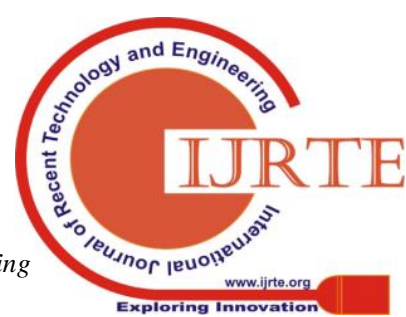


2. wherein rectangular stick tool encourages the integration interest from the top to the neckline and dodges the choppiness, there by using this equipment profile is ok for buying imperfection loose welds.

3 . From the consequences apparatus revolution pace is the precept enter parameter that has the first-rate measurable impact on mechanical houses like, elasticity, weakness and hardness.

4. Experimented critiques of AA3003-6082, AA6082-64430 and AA3003-64430 aluminum joints, wherein aluminum joint of AA6082-AA64430 demonstrating greater noteworthy susceptible factor existence contrasted with one-of-a-kind joints and to the joint AA3003-6082 acquired most immoderate pliable houses too joint AA3003-AA64430 receives best hardness.

5. Micro-hardness space displayed considered one of a type weld joint hardness profiles, in which low hardness changed into received at the welding consciousness. AA3003-AA64430 joint plots hardness at left half of of the bottom steel as 62.5 , hardness amount right $1 / 2$ of of the bottom steel as sixty 4.five and dwindled to fifteen.5 on the welding awareness. AA3003-AA6082 joint plots hardness at left half of of the base metal as 59.5, hardness variety at proper half of of the base metallic 63.five and decreased to 17.five at the welding interest. just as AA6082-AA64430 joint plots hardness at the bottom metallic as 61.5, right element hardness wide form of the lowest metallic sixty two. 5 and decreased to 15 on the weld attention. The most excessive hardness esteem sixty three.five of the AA3003-AA64430 joint.

6. Tool pivot is most intense, results joint of AA3003-AA6082 stress is excellent contrasted with unique joints. Be that as it can, expanding the warm temperature data speed reducesthe weld velocity bringing approximately littler TMAZ and HAZ which turns on more distinguished strain.

7. The examples had been defined through manner of strategies for pressure, hardness and increasing. From the exam it is located that in welding price decline, actually as increment in instrument revolution speed, diminishes the tension.

8. The grinding combination welds made on AA3003-AA6082, AA6082-AA64430, and AA3003-AA64430 aluminum compound of 4mm thickness were located to have sufficient pliability beneath streamlined weld situations with rectangular stick device profile.

\section{REFFERENCES}

1. G. Bussu and P.E. Irving "The interest of final pressure and warmth stimulated area houses on exhaustion cut up engendering in touch combination welded 2024-T351 aluminum joints" InternationalJournal of Fatigue 25 (2003) 77-88.

2. Vivekananda, Arunachalam.V. P, Prakash. T.L.Savadamuthu, "The Experimental analysis of Friction Stir Welding on Aluminum Composites" international journal of MetallurgicalEngineering, four(2012).

3. A. Simar, Y. Brechet, B. De Meester, A. Denquin, and T. Pardoen "Microstructure, network and international mechanical homes of erosion mix welds in aluminum composite 6005A-T6" MaterialsScience and Engineering, 486 (2008) 85-ninety 5.

4. J.Q. Li and H.J. Liu(200) "influences of hardware flip velocity on microstructures and mechanical homes of
AA2219-T6 welded by way of way of the outdoor non-rotational shoulder helped touch combo welding" materials and layout forty 3 (2013) 299-306.

5. M.N. James,D.J. Hughes, Z. Chen , H. Lombard, D.G. Hattingh ,D.Asquith, J.R. Yates andP.J. Webster "Leftover anxieties and exhaustion execution" Engineering Failure analysis 14(2007) 384-395.

6. 6.N. T. Kumbhar and k. B.Murthy, "Grinding Stir Welding of Al 5052 with Al 6061 Alloys, "Diary of metallurgy, quantity 2012, Article id 303756,no.7,2012.

7. J. C.Park, S. J. Kim, "The impact of journeying and Rotation Speeds on Mechanical residences throughout Friction Stir Welding of numerous Al Alloys", defect and Diffusion discussion board, quantity. 297-301, pp. 590-595, 2010.

8. C. Leitao, R.M. Leala, , D.M. Rodrigues, A.Loureiroa, and P.Vilacac,"Mechanical conduct of comparative and disparate AA5182-H111 and AA6016-T4 narrow rubbing mixture welds," extent 30 , difficulty 1 , Pages one zero one-108,2009.

9. S Benavidesa,YLia, L.E Murra, D Brown and J.C McClure, "Low-temperature grinding blend welding of 2024 aluminum," magazine of Script material , extent forty one, issue 8, pp 809-815,1999.

10. C.G. Rhodes, M.W. Mahoney, W.H. Bingel, R.A.Spurling and C.C.Bampton, "influences of grinding combo welding on microstructure of 7075 aluminum," journal Script material volume 36,issue 1, pp sixty nine-seventy five, 1997.

11. H Fujita and T Tabatha, "The impact of grain length and disfigurement sub-structure onMechanical homes of polycrystalline aluminum," magazine Act Metallurgic, volume 21,issue four, pp 355-365, 1973.

12. Yutaka S Satoa, MitsunoriUrata, Hiroyuki Kokawa, Keisuke Ikedaa and Masatoshi Enomoto, "upkeep of nice grained microstructure of equal channel specific squeezed aluminum compound 1050 thru rubbing mix welding," magazine of Script fabric extent forty five, trouble 1, pp 109-114, 2001

13. L.E. Svensson, L. Karson, H. Karlsson, B. Karlsson, M. Fazzini and J. Karlsson,"Microstructure and mechanical residences of rubbing combination welded aluminum compounds with remarkable connection with AA 5083 and AA 6082," magazine of technological know-how And generation Of Welding And becoming a member of volume. 5, Iss.five, 2000.

14. M. W. Mahoney, G. Rhodes, G. Flintoff, H. Bingel and R.A.Spurling, "residences of rubbing mix welded 7075 T651 aluminum," journal of Metallurgical and MaterialsTransactions, volume 29, issue 7, pp 1955-1964.1998.

15. A.k. Vasudeva and R.D. Doherty, "Grain restrict pliable crack in precipitation solidified aluminum compounds," magazine of Act Metallurgical quantity 35, difficulty 6, pp 1193-1219, 1987.

16. P. Sue, A.Gerlich, T.H. North and G.J. Bendzsak, "Intermixing in varied Friction Stir Spot Welds," journal of Metallurgical and materials Transactions, extent 38, trouble 3, pp584-595, 2007.

17. Y. Li,R.D. Flores,L.E.Murr , A.Trillo and McClure ,"Intercalation vortices and relatedMicro primary highlights inside the grating combination welding of specific metals," journal of MaterialResearch Innovation, volume 2, problem 3, pp a hundred fifty-163, 1998.

18. H. M. Jamalian, M. Farahani, M. k. B.Givi and M.AghaeiVafaei, "influences of touch combo welding

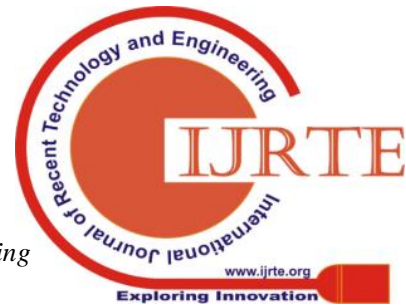


device parameters on the microstructure and mechanical homes of 5086 H34 aluminum welded joint," magazine of superior production era, extent eighty three, problem $1, \mathrm{pp}$ 611-621, 2016.

19. SathishRengarajan and V.Seshagiri Rao, "attributes of aa7075-t6 and aa6061-t6 rubbing welded joints," journal of Transactions of the Canadian Society for MechanicalEngineering, extent.39, No. 42015.

20. G.H.Payganeh,N.B.MustafaArab,Y.DadgarAsl,F.A.Ghas emi andM.S.Boroujeni, "affects of rubbing blend welding system parameters on look and exceptional of polypropylene composite welds," journal of the physical Sciences extent. 6(19), pp. 4595-4601, sixteen September, 2011. 